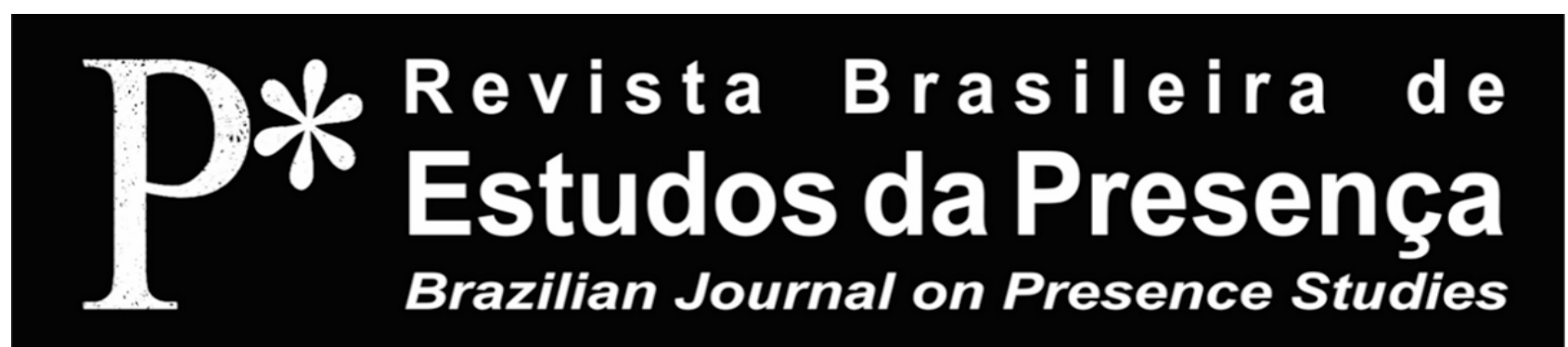

PROCESSOS DE CRIAÇÃO

E-ISSN 2237-2660

\title{
Investigações Subterrâneas: perspectivas errantes e modos de expressão
}

\author{
Rodrigo Fischer' \\ Roberta Kumasaka Matsumoto' \\ 'Universidade de Brasília - UnB, Brasília/DF, Brasil
}

RESUMO - Investigaçóes Subterrâneas: perspectivas errantes e modos de expressão - O artigo objetiva investigar o processo de criação do projeto interdisciplinar $A$ sombra dos outros, realizado pelo Grupo Desvio, na cidade de Nova Iorque, a partir de uma imersão errante no universo subterrâneo da cidade. Esse processo foi realizado por meio de procedimentos estéticos e filosóficos que buscavam desestabilizar e descentralizar noções como corpo, indivíduo e representação. Este ensaio apresenta então procedimentos que permitem a reconfiguração de modos de expressáo e a instauração de um plano que permita novas percepçóes e novos modos de existência.

Palavras-chave: Processo criativo. Subterrâneo. Errância. Modos de Expressão. Modos de Existência.

ABSTRACT - Underground Investigations: wandering perspectives and modes of expression - This paper aims to investigate the creative process for the interdisciplinary project The shadow of others. The project was produced by the theater company Grupo Desvio and based on a wandering immersion in New York City's underground universe. This process was developed through aesthetic and philosophical procedures to destabilize and decentralize notions such as body, individual and representation. The research presents procedures that enable a reconfiguration of the modes of expression and the establishment of a plan to allow for new perceptions and new modes of existence. Keywords: Creative Process. Underground. Wandering. Modes of Expression. Modes of Existence.

RÉSUMÉ - Enquêtes Souterraines: perspectives errantes et modes d'expression - L'article vise à enquêter sur le processus de création du projet interdisciplinaire L'ombre des autres réalisé par le Grupo Desvio, à New York, à partir d'une immersion errante dans l'univers souterrain de la ville. Ce processus a été mené à travers des procédures esthétiques et philosophiques qui visaient à déstabiliser et décentraliser des notions telles que le corps, l'individu et la représentation. Cet essai présente donc, les procédures qui permettent de reconfigurer des modes d'expression et d'établir un plan qui rend possible des nouvelles perceptions et des nouveaux modes d'existence.

Mots-clés: Processus Créatif. Souterrain. Errance. Modes d'Expression. Modes d'existence. 


\section{Resistir ou Re-existir: a invisibilidade subterrânea e seu modo de exis- tência}

Poderíamos dizer que um processo criativo em artes cênicas geralmente ocorre a partir de uma percepçáo específica de mundo até a sua elaboração estética, que evidencia tal percepção. Essa noção de mundo pode originar-se da realidade, da imaginação, da sensaçáo, da memória, da experiência, do sonho ou mesmo de uma percepção atravessada por tudo isso. Já a elaboração estética pode transitar entre a representação desse mundo, ou seja, tornando presente tal noção no espaço cênico, e a performatividade dele: a noçáo de mundo sendo a própria materialidade dos corpos e dos objetos no espaço cênico. O teatro contemporâneo, como trazem tantos autores, transita entre essas duas esferas, com uma ênfase, principalmente a partir dos anos 1990, na esfera performativa. A presente reflexão, que tem como ponto de partida um processo criativo, almeja discutir a esfera estética desse processo questionando, dentre outros aspectos, noçáo de representaçáo e, do mesmo modo, intenta refletir sobre como essa esfera precisa estar alinhada com a urgência de se reconfigurar uma noçáo de mundo.

A urgência é entendida aqui como algo especialmente necessário dentro de um contexto político que aspira ao controle de nossos corpos, de nossa subjetividade e de nossos modos de existência. A arte, que comumente está do outro lado, ou seja, afrontando a esse controle, necessita pensar meios urgentes de resistir ou de re-existir. $\mathrm{O}$ processo criativo que será discutido aqui compreende a resistência a partir da ideia de re-existência, ou seja, como possibilidade de se pensar novos modos de existir e novos circuitos afetivos.

O objeto do presente estudo é o processo de criaçáo do projeto interdisciplinar $A$ sombra dos outros, uma criação do Grupo Desvio ${ }^{1}$. A obra foi conduzida por um dos autores do presente artigo, Rodrigo Fischer, durante sua pesquisa de campo do pós-doutoramento ${ }^{2}$ realizada no Departamento de Estudos da Performance da New York University, entre junho de 2017 e agosto de 2018, na cidade de Nova Iorque. Se a pesquisa de pós-doutorado, de um modo geral, era delimitada pelo conceito de polifonia na composição de um solo teatral e suas possíveis correlaçóes com imagens e novas tecnologias, a pesquisa de campo em Nova Iorque foi configurada a partir de um 
modo de expressão interdisciplinar e incluiu a ideia de agenciamento com objetos. É com base nesse recorte que a presente reflexáo se configura.

Considerando que a pesquisa tem um caráter teórico-prático, além da criaçáo da obra mencionada, ela objetiva pensar possíveis agenciamentos entre corpo, objeto, imagem, som e novas tecnologias para criação cênica, com supervisão, na etapa de Nova Iorque, do professor André Lepecki. A criação nasce então de duas instâncias simultâneas, sendo a primeira o romance Notas do Subterrâneo, de Fiódor Dostoiévski (1983), e a segunda pela possibilidade de pesquisar possíveis descentralizaçôes e desconstruçôes do corpo orgânico a partir de seu agenciamento com outros corpos inorgânicos, todos inseridos na mesma categoria de coisas, como será contextualizado ao longo do texto. Essa perspectiva permite entender que o intuito de se descentralizar a hierarquia entre sujeito e objeto é também para que se possa encontrar novos modos de subjetivaçáo e novos modos de existência.

O livro Notas do Subterrâneo, traduzido também como Memórias do Subsolo, foi originalmente publicado em 1864. Trata-se de um texto que narra uma contraditória revolta e a frustração de uma personagem diante de seus relacionamentos, diante de si próprio e diante da sociedade. É a narrativa sobre alguém que vive marginalizado no seu subsolo, uma figura que não se adéqua ao sistema, seja por numa perspectiva pessoal, social ou política. Esse é também o mote do projeto $A$ sombra dos outros, que busca um diálogo com a cidade, afetar e ser afetado por ela, a fim de entender o que seria e o que pode ser caracterizado como subterrâneo-submundo, quem são as pessoas desse espaço e como elas agem perante o contexto político em que estão inseridas. A proposta dessa criação é então a de reconfigurar possíveis correlaçóes entre corpos, objetos, imagens, sons e arquiteturas por uma perspectiva que jogue luz na tensão política inerente ao direito à cidade e à mobilidade em oposição às nossas prisóes sociais e ao controle da subjetividade. A ideia é compreender possíveis formas de visibilizar corpos, objetos, imagens, sons e arquiteturas que são descartados, invisibilizados, oprimidos, inutilizados, tortos e que perderam seu valor social, utilitário ou estético.

Esta perspectiva, de buscar a potência de coisas invisibilizadas, é discutida no livro Existências mínimas (2017) de David Lapoujade, que, ao fazer uma reflexão do texto de Étienne Souriau, em seu livro Os diferentes modos 
de existência (2017), entende que as existências mínimas seriam existências que náo materializaram suas potencialidades dentro de uma realidade e por isso permanecem apenas como potências virtuais. Trata-se de existências orgânicas e inorgânicas que possuem capacidades de se efetivarem ou de se inserirem dentro de uma possível realidade, mas que permanecem invisibilizadas, permanecendo na condiçáo de potência, ou seja, como virtualidades. O virtual para Lapoujade, e também para Deleuze (2006), é compreendido como a potência presente nas coisas (matérias, objetos, corpos, espaços e seres), que só deixam de ser unicamente virtuais quando são materializadas ou quando sáo atualizadas. Para Lapoujade (2017, p. 36) "Os virtuais estáo aí, à nossa volta, eles aparecem, desaparecem, se transformam, à medida que a própria realidade muda; eles não têm nenhuma solidez, nenhum lugar determinado, nenhuma consistência”. Na perspectiva de Lapoujade (2017, p. 41), as existências mínimas precisariam passar por um processo de instauração para aumentarem seu grau de realidade.

Como pode um ser, no limite da inexistência, conquistar uma existência mais 'real', mais consistente? Com que gesto? Qual é a 'arte' que permite que as existências aumentem sua realidade? São provavelmente as existências mais frágeis, próximas do nada, que exigem com força tornarem-se mais reais. É preciso ser capaz de percebê-las, de aprender seu valor e sua importância. Portanto, antes de colocar a questão do ato criador que permite instaurá-las, é preciso se perguntar o que é que permite percebê-las.

No entendimento de Lapoujade e Souriau, é preciso entáo olhar e aprender a perceber as virtualidades, que podem se instaurar ao se tentar modificar o próprio ponto de vista e ter um olhar mais participativo. Ou seja, "nossa perspectiva se encaixa em outra perspectiva", pois cada modo de existência possui sua própria lógica e seu próprio ponto de vista. Para Lapoujade (2017, p. 47), "náo temos uma perspectiva sobre o mundo, pelo contrário, é o mundo que nos faz entrar em uma de suas perspectivas".

\section{A Errância como Processo}

O processo criativo de $A$ sombra dos outros começa entáo com a ideia de vagar e olhar a cidade de Nova Iorque de modo a enxergar pessoas, arquiteturas, imagens e objetos por diferentes perspectivas, buscando assim instaurar suas potências, que se encontram ainda numa esfera virtual. Este trabalho, de participar de outros modos de existência, durante aquilo que 
definimos como um vagar errante, objetivava reconfigurar nossa própria existência e a relação com a cidade, além de buscar meios de potencializar as virtualidades dessas existências mínimas e invisíveis. Ou, como prefere Lapoujade (2017, p. 84), meios de afirmar os direitos dessas existências, de tentar fazer "um mundo novo, quebrando as estruturas antigas em prol de uma nova cosmicidade". Lapoujade (2017, p. 103) propóe meios de potencializar modos de existências tanto pelo processo de anáfora, que "é o processo pela qual uma existência tenta conquistar mais realidade", quanto pelo processo de instauraçáo, "gesto pelo qual a existência quer afirmar o direito de existir" e legitimar um modo de ocupar um espaço-tempo.

O trabalho de vagar pela cidade exigia "[...] ora em permanecer em um mesmo plano de existência, ora em reunir dois planos cujos modos de ser são radicalmente distintos" (Lapoujade, 2017, p. 76). Como reconfigurar nosso ponto de vista diante das coisas, diante do mundo? Como se colocar no ponto de vista de outro modo de existência? Lapoujade (2017) sugere em seu texto que os processos de instauraçáo se materializam principalmente por uma perspectiva de redução. Para ele "[...] é preciso purificar o campo da experiência de tudo aquilo que impede ver. Nesse sentido, reduzir é liberar um plano de experiência pura" (Lapoujade, 2017, p. 48). O desafio desse caminhar errante em Nova Iorque foi entáo o de reconfigurar nossa perspectiva de olhar as coisas e a cidade, tentando nos colocar em outros modos de existência por meio de uma experiência menos contaminada, logo, com a tentativa de desconstruir ou despossuir pensamentos engessados e préestabelecidos.

Qual a potência afetiva dessas coisas descartadas ou desprezadas socialmente, desses outros modos de existência? Quais as narrativas que elas constroem? Durante esse vagar, o idealizador, diretor e performer do projeto, Rodrigo Fischer, acompanhado da artista visual Yasmin Santana e do cineasta Peter Azen, começaram a captar e a coletar coisas nas ruas: lixos, objetos, histórias, e, principalmente, o registro audiovisual dessa caminhada errante que buscava olhar o subterrâneo da cidade. $\mathrm{O}$ desafio dessa errância era o de instituir um estado de vulnerabilidade e de estar à deriva, permitindo ser afetado pelas coisas que atravessavam o caminho. O processo, já desde esse momento, priorizava um constante estado poroso e rizomático, aberto às interferências e mudanças, no qual os encontros, os acasos, as des- 
cobertas, os desvios e qualquer coisa que atravessasse o caminho, por meio da afetividade, permitissem que a poética, o modo de expressar e o discurso da criação se configurassem durante o próprio processo.

Se um dos objetivos dessa investigaçáo cartográfica, dentro desse universo subterrâneo, numa busca de potencializar a virtualidade de existências mínimas, era o de reconfigurar também nosso ponto de vista diante das coisas, o mergulho nessa geografia de afetar e deixar-se ser afetado pela cidade foi fundamental para o processo criativo. Foi ainda durante essa errância pelas ruas de Nova Iorque que a compreensão desse corpo, que busca despossuir seus engessamentos prévios e vibra com as notas que cada espaço emite, foi sendo estabelecida. Em outras palavras, a busca por esse estado de escuta, de experiência e atravessamento dos afetos, permitiu, no decorrer do processo, que as virtualidades orgânicas e inorgânicas, dentro do universo subterrâneo, se tornassem, de alguma maneira, visíveis e atuais. A percepção dessas existências mínimas vibrava em nosso corpo como artistas-observadores que desejam a reinvenção de si. Estávamos interessados, antes de mais nada, em reconfigurar nossa sensibilidade, nosso ponto de vista e um entendimento de mundo, numa busca incessante de fazer vibrar as potencialidades virtuais, para assim poder pensar novas paisagens existenciais ou novos modos de existência.

Durante a imersão errante pelas ruas de Nova Iorque, o propósito era também o de captar e coletar possíveis materiais para a criação. De modo mais prático, os já mencionados artistas Yasmin, Peter e Rodrigo escolhiam, a cada dia de imersáo, bairros ${ }^{3}$ distintos de Nova Iorque e caminhavam à deriva nessa constante busca de olhar para a cidade por diferentes perspectivas e tentar entender como e o que seria o subterrâneo de cada espaço visitado, fazendo o exercício de vislumbrar suas invisibilidades. Uma importante reflexão durante a imersão foi a de entender que as coisas inorgânicas (objetos) se configuram em lixos quando perdem seu valor utilitário, e o mesmo acontece em relação às coisas orgânicas (pessoas), ou seja, quando as pessoas perdem seu valor social, elas são também descartadas da sociedade por não serem mais úteis a ela. Tal perspectiva, de pensar que as coisas orgânicas e inorgânicas alcançam uma nova configuração, quando são desconectadas de sua função ou utilidade dentro dessa lógica mercadológica, implica também no fato de que elas "[...] revelam a sua capacidade liberadora, a sua 
capacidade de escapar totalmente de dispositivos de captura" (Lepecki, 2012, p. 96). Compreender as coisas inúteis imbricadas nesse contexto foi importante para a delimitação da pesquisa em pensar possíveis descentralizaçóes e despossessóes do corpo orgânico a partir de seu agenciamento com outros corpos inorgânicos.

Quais eram as coisas, pessoas, arquiteturas e narrativas que não instauravam suas virtualidades, não se atualizavam por serem existências mínimas, marginalizadas, abandonadas e invisíveis dentro da cidade de Nova Iorque? Arquiteturas abandonadas, paisagens destruídas, lugares sombrios, lixos, objetos inúteis, destroços, pedreiros, ambulantes, lixeiros, artistas de rua, pedintes, transeuntes, moradores de rua, errantes solitários, todas essas coisas estavam predominantemente numa esfera invisível. Todas essas coisas interessavam serem percebidas por nós. É a partir desse material que a obra foi composta.

A imersão aconteceu primeiramente nas ruas de diversas áreas de $\mathrm{Ma}$ nhattan, Brooklyn e Queens. Algumas coisas começaram a chamar mais nossa atençáo, como os lixos descartados (Figura 1) na porta das casas, algo comum em quase todas as ruas de Nova Iorque.
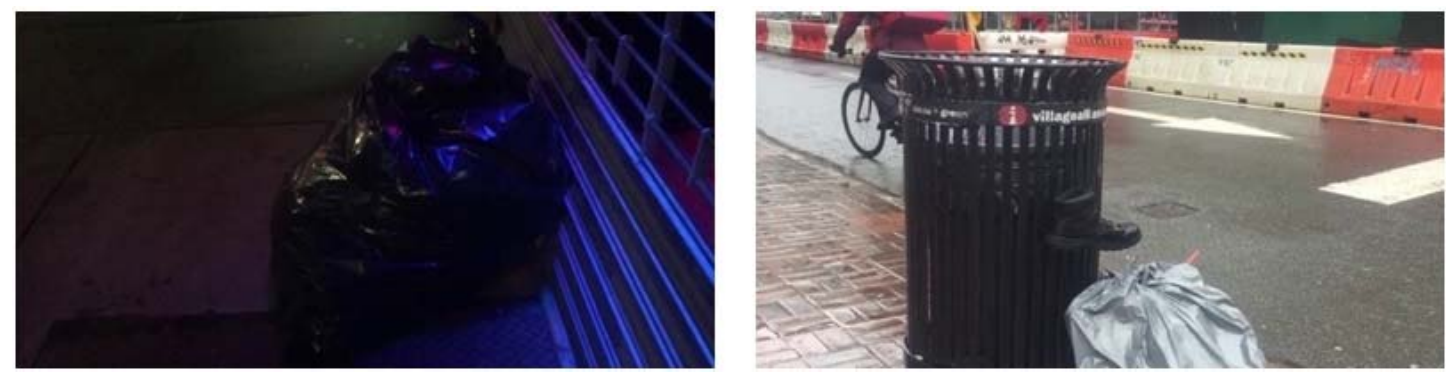

Figura 1 - Lixos descartados. Fonte: Capturas de tela dos vídeos realizados pelo cineasta do projeto Peter Azen e pelo diretor Rodrigo Fischer entre setembro de 2017 e maio de 2018 na cidade de Nova Iorque.

Esses lixos abandonados na porta das casas serviram náo apenas para o registro audiovisual que viria a compor a videoinstalação e como materiais coletados que compuseram as obras visuais e interativas do trabalho, como veremos a seguir, mas também traziam muitas reflexôes que nos provocaram a pensar a obra: apesar de os lixos serem bastante homogêneos como embalagens, quais as particularidades de cada lixo? Como e por que esses objetos foram descartados? Será que eles simplesmente perderam sua utilidade? Eles não poderiam ser úteis em outros contextos? Qual a história por trás de cada objeto descartado? O que a pessoa, que descartou um pote de iogurte, estava 


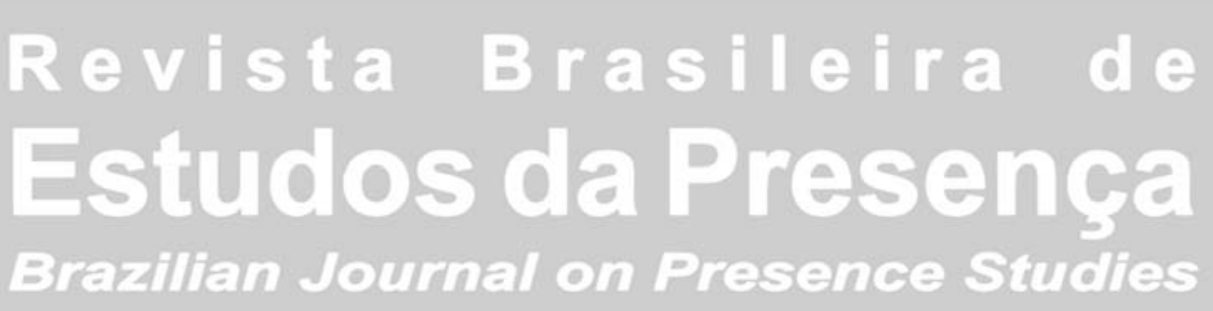

E-ISSN 2237-2660

pensando enquanto comia? E a marca de batom na latinha de cerveja? Quais narrativas atravessavam aqueles objetos e lixos? Todas essas perguntas reverberaram em nossas reflexóes ao longo desse processo. Ao observar os lixos da cidade, começamos também a enxergar que alguns acúmulos de lixos eram, como imagens, não apenas sujeiras, mas traziam em si uma potência poética de composição, como podemos observar nas imagens a seguir (Figura 2):
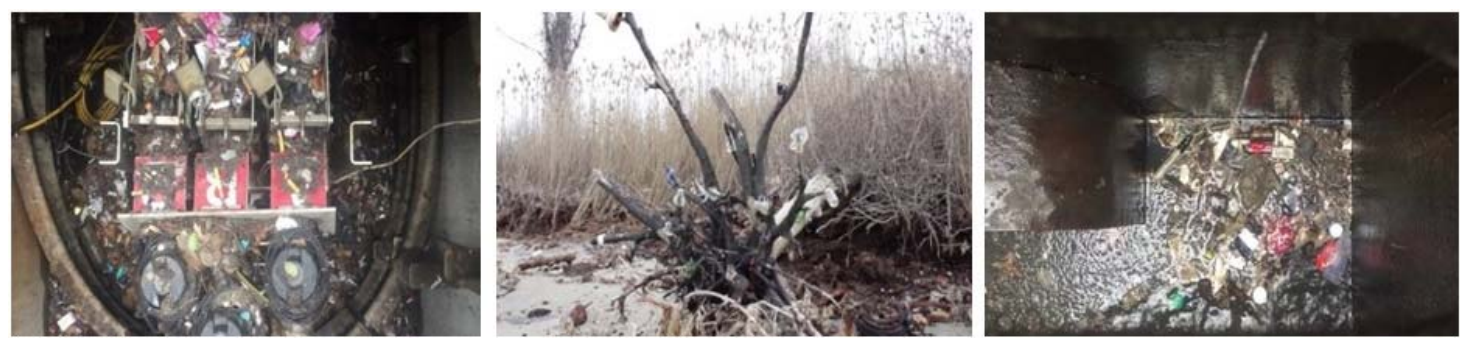

Figura 2 - Lixos instalaçóes. Fonte: Capturas de tela dos vídeos realizados pelo cineasta do projeto Peter Azen e pelo diretor Rodrigo Fischer entre setembro de 2017 e maio de 2018 na cidade de Nova Iorque.

Olhar para o acúmulo de lixos como composiçáo poética de imagem nos instiga a pensar na possibilidade de outros modos de expressáo que não estão subordinados a um pensamento hegemônico de experiência estética. Se o subterrâneo é habitado e permeado por coisas que não se adaptam a um sistema e que possuem sua própria lógica de organização, será que a nossa sensibilidade de criação náo deveria também questionar nossa forma subordinada a padronizaçóes estéticas?

Durante esse trabalho, além de perambular pelas ruas, fomos encontrando algumas paisagens que certamente não estavam no roteiro de nenhum turista, mas que traziam em sua composição algo bastante peculiar e espetacular. Dois desses lugares foram bastante impactantes, o Dead Horse Bay, uma praia com acúmulo de garrafas e descartáveis, e uma área abandonada de Red Hook com agrupamentos de lixos e com vista para a estátua da liberdade, ambos no Brooklyn, como podemos ver na figura a seguir (Figura 3):
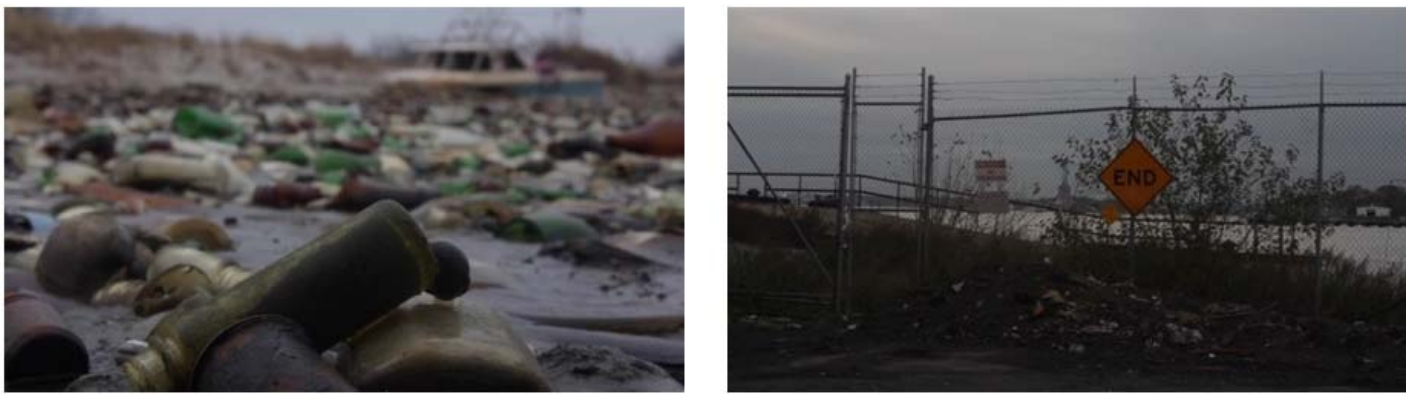

Figura 3 - Paisagens e destroços. Fonte: Capturas de tela dos vídeos realizados pelo cineasta do projeto Peter Azen e pelo diretor Rodrigo Fischer entre setembro de 2017 e maio de 2018 na cidade de Nova Iorque. 


\section{$x^{\text {romanat }}$ B rasileira

Essas paisagens sintetizavam o abandono e a invisibilidade desproporcional presente nas grandes cidades. Como é possível uma praia de garrafas ao lado de uma ponte no Brooklyn? Como é possível tanto lixo e entulho cercados por uma grade numa cidade que tem a estátua da liberdade como símbolo? Como é possível caminhar nas ruas de Nova Iorque e não perceber a quantidade de pessoas ali abandonadas? Todas essas inquietaçóes interferiram em nosso processo de criaçáo.

Ainda sobre esse vagar errante com o intuito de ressignificar nosso olhar por uma perspectiva subterrânea, foi importante ir literalmente para debaixo da terra, para um dos lugares mais movimentados da cidade: o metrô.

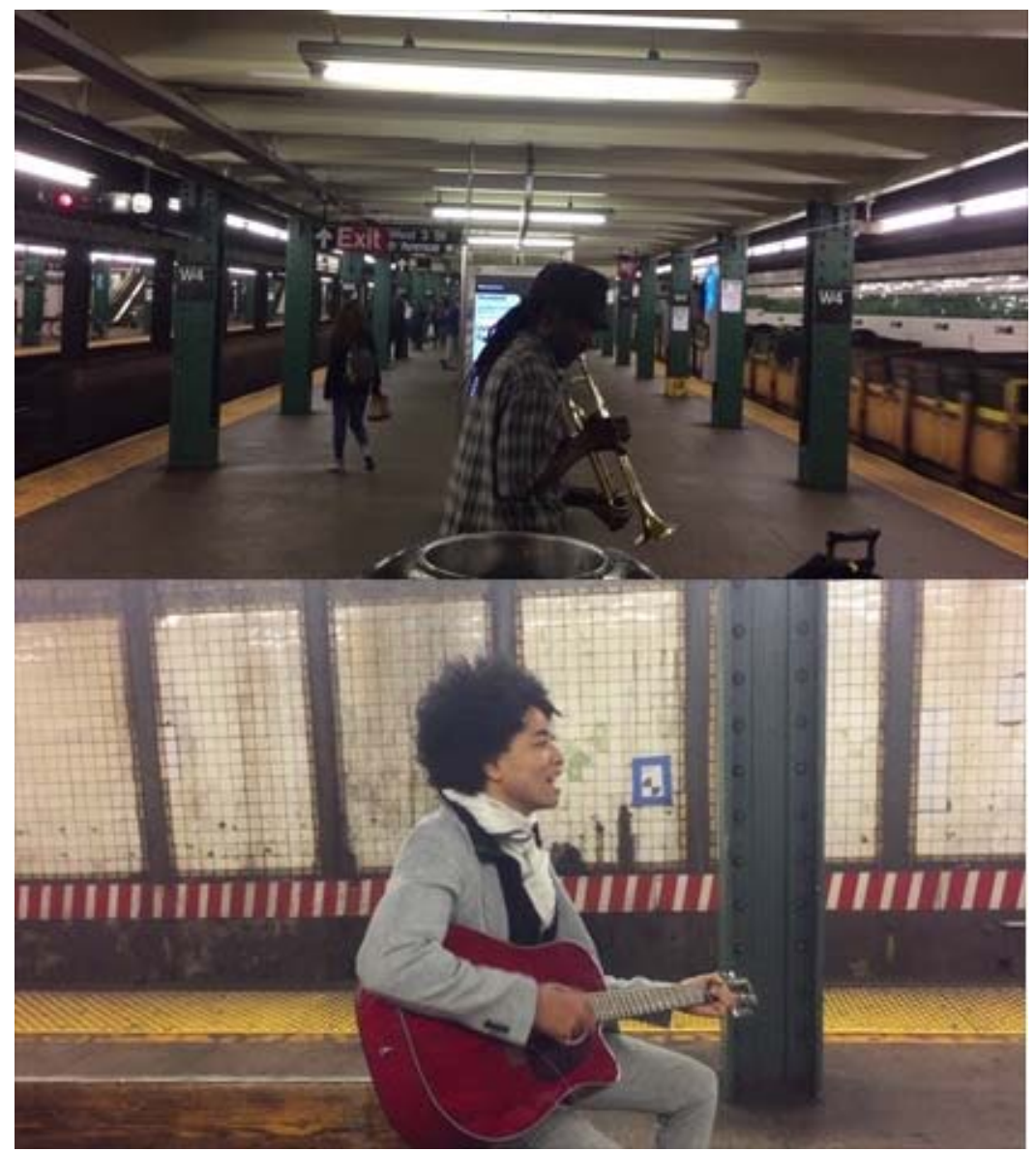

Figura 4 - Estaçáo de metrô em Nova Iorque e os artistas. Fonte: Capturas de tela dos vídeos realizados pelo cineasta do projeto Peter Azen e pelo diretor Rodrigo Fischer entre setembro de 2017 e maio de 2018 na cidade de Nova Iorque.

O metrô de Nova Iorque é mundialmente conhecido por sua diversidade, por sua logística e pelas figuras peculiares que por ali passam, assim como por sua sujeira, ratos e artistas que, certamente, aliviam o tédio que os 
passageiros enfrentam em seu dia a dia (Figura 4). Esses motivos já seriam suficientes para nossa imersão, mas queríamos entender também a dinâmica daquele espaço por outras perspectivas. Para a pesquisa, a percepçáo mais importante que tivemos, nesse espaço subterrâneo das estaçóes e vagóes do metrô, foi a de que ali as invisibilidades gritam e imploram para serem vistas. Em Nova Iorque, principalmente nos metrôs, salienta-se uma impressáo de invisibilidade. Se por um lado isso é positivo, permitindo uma sensação maior de liberdade, já que as pessoas podem se sentir mais à vontade para se mostrar do jeito que elas quiserem, por outro, as invisibilidades são ainda mais ocultas. Náo apenas por aqueles que dormem todas as noites no mesmo vagáo de trem, pelos pedintes, pelos artistas que, se náo forem realmente virtuosos, passam despercebidos, mas também por aqueles que estấo ou se sentem, em alguma instância, deslocados no mundo. Quais as histórias dessas pessoas? Como elas se sentem no meio de tantas pessoas que náo enxergam seus corpos e suas potencialidades?

Um dos fatores mais impressionantes durante a imersão foi o de perceber que, apesar da aparente invisibilidade das coisas que atravessavam nossa errância, sejam elas coisas orgânicas ou inorgânicas, era possível imaginar que muitas narrativas trespassavam aqueles espaços, aquelas paisagens, aquelas pessoas e objetos. Com o registro audiovisual, a coleta dos objetos, as entrevistas e, sobretudo, a experiência dessa imersáo, o próximo passo da criação foi então encontrar formas de agenciar esse material. Foi nessa etapa que o âmbito da pesquisa, ao se pensar possíveis descentralizaçóes e despossessôes do corpo orgânico a partir de seu agenciamento com outros corpos inorgânicos, começou a conduzir às prováveis formas de agenciar o material coletado. Agenciamento é entendido aqui por uma perspectiva deleuziana, na qual todo esse material coletado náo seria trabalhado por sua possibilidade de representação e significado, mas sim em razão das múltiplas tensôes geradas na correlação entre suas materialidades.

Pensar a composição do material por meio da ideia de agenciamento é, sobretudo, pensar numa organização que priorize a multiplicidade da relação entre cada matéria, sem anular suas singularidades. É entender a potencialidade de cada elemento para assim permitir possíveis sobreposiçóes, justaposiçóes e fusóes. Se o discurso do projeto teve como ponto de partida o texto de Dostoiévski, que se desdobrou numa imersão urbana para se com- 
preender a potencialidade das coisas virtuais, a etapa a seguir configurou-se no desejo de pensar a forma de agenciar e expressar o material coletado: 150 horas de registro audiovisual; dez caixas com objetos encontrados, lixos e materiais descartáveis; quinze entrevistas com pessoas que nos atravessaram em nossas andanças; centenas de caixas de papeláo dobradas que serviriam como suporte para projeção; e a experiência de olhar a cidade de Nova Iorque por outras perspectivas.

Importante enfatizar que, durante a imersão, buscávamos uma experiência de horizontalidade com todas as coisas que atravessavam nossas andanças, com o intento tanto de pensar possíveis relaçóes entre corpos e objetos quanto para suspender a relação de posse e poder entre sujeito e objeto. Essa percepção provocou uma grande inquietação, discutida neste estudo: descentralizar a noção de corpo e despossuí-lo de suas construçóes sociais e engessamentos náo seria um procedimento de reconfiguraçáo da subjetividade, permitindo consequentemente pensar novos modos de existência?

Esta busca por uma relação horizontal entre sujeito e objeto conduziunos à pesquisa do professor André Lepecki, com a qual passamos a entender todas as coisas, humanas e não humanas, orgânicas ou inorgânicas, simplesmente como coisas, a fim de suspender qualquer forma de hierarquia ou posse, colocando lado a lado corpo e objetos. Para Lepecki (2012, p. 98):

Esse simples ato de colocar coisas em sua quietude, imobilidade e concreta coisidade ao lado de corpos, não necessariamente junto com os dançarinos, mas lado a lado, resulta em um evento substancial: sublinha a estreita linha que simultaneamente separa e une corpos e coisas, delineia uma zona de indiscernibilidade entre o corporal, o subjetivo e a coisa.

Esse entendimento de horizontalidade entre as coisas, para Lepecki, provoca ainda pensarmos novas formas de subjetivaçáo entre o sujeito e o objeto, questionando uma ordem política de posse e poder. Ele entende que “[...] objetos, quando libertos de utilidade, valor de uso, valor de troca e significação, revelam a sua capacidade libertadora" (Lepecki, 2012, p. 98). Durante a imersão, ao nos depararmos com inúmeros objetos descartados e jogados nas ruas, buscávamos subverter a lógica de encontrar e possuir os objetos, deixando que eles nos encontrassem. Nosso exercício era o de olhar as coisas não pela perspectiva daquilo que elas representavam, significavam ou valiam, mas o de olhar a coisa em si, sua materialidade, sua potência co- 
mo forma e vibração. Uma compreensão próxima à dos ready-mades de Marcel Duchamp, ou seja, privando-os de sua funçáo original e utilitária, reduzindo o objeto à matéria em si.

\section{Reconfiguraçóes a partir de Processos de Redução, Desamparo e Esgo- tamento}

O procedimento de reduzir ou esvaziar o significado e a representação dos objetos foi algo que acompanhou todo o processo criativo de $A$ sombra dos outros. A redução é entendida como a primeira etapa de um processo para instaurar virtualidades, como já foi mencionado pela perspectiva de David Lapoujade, e também como forma de potencializar a matéria, reduzindo suas possíveis formas de representação. Para Lapoujade (2017, p. 48):

A importância da redução, em geral, é instaurar um plano que torne possível a percepçáo de novas entidades. Trata-se de fazer ver, de tornar perceptivas novas classes de seres, até os que são invisíveis. A redução é, primeiramente, uma operação de limpeza. É preciso purificar o campo da experiência de tudo aquilo que impede ver.

Reduzir como um procedimento de limpar nossas preconcepçóes e buscar novos entendimentos das coisas e novos entendimentos de mundo, permitindo, assim, novos modos de existência. Se o processo de instauraçáo de novos modos de existência acontece por meio de um processo de redução, como sugere Lapoujade, ou seja, para estabelecer aquilo que ele chama de experiência pura, seria preciso despossuir ou despossessar a noçáo de indivíduo que construímos, seja como uma construção social, política ou identitária. Esse processo de desindividuação, de desprendimento da noção de indivíduo e de sua autorrepresentação, é apreendido aqui tanto pelo viés da redução, quanto por aquilo que Vladimir Safatle (2016) entende como uma política do desamparo.

Safatle, em seu livro $O$ circuito dos afetos: corpos políticos, desamparo e o fim do individuo, propóe que o processo de desindividuaçáo, por meio de despossessóes da noção do indivíduo a partir do desamparo, seria um meio de impulsionar o sujeito a se abrir para um processo de transformação. Obviamente ele requalifica aquilo que entendemos por desamparo, principalmente a partir da psicanálise de Sigmund Freud. Para Safatle, é vital não confundir o desamparo com o medo. Este estaria conformado a uma política afetiva de poder e controle, baseada num modo de sujeição, enquanto que o 
desamparo é reconhecido dentro de uma política afetiva na qual o desamparado, em razáo das possibilidades de despossessão, lida com afetos que podem instaurar modos de liberaçáo. $\mathrm{O}$ desamparo, dessa forma, possibilita um outro circuito afetivo e, consequentemente, novas formas de existir. Para ele, ao contrário do medo, o "desamparo não é algo com o qual se luta, mas algo que se afirma" (Safatle, 2016, p. 18). O medo é ancorado num sistema prévio de representaçáo, que conduz para algo determinado e estabelecido, enquanto o desamparo desestabiliza qualquer noçáo de representaçáo e conduz para um estado de potência que implica libertar o sujeito da própria categoria de indivíduo. Para Safatle (2016, p. 21-22):

Um corpo político produzido pelo desamparo é um corpo em contínua despossessão e desidentificação de suas determinaçôes. Corpo sem $e u$ comum e unicidade, atravessado por antagonismos e marcado por contingências que desorganizam normatividades impulsionando as formas em direção a situaçôes impredicadas. Por isso, o desamparo produz corpos em errância, corpos desprovidos da capacidade de estabilizar o movimento próprio aos sujeitos através de um processo de inscrição de partes em uma totalidade.

Estar desamparado, dentro dessa perspectiva, é permitir ser afetado por algo que o despossui daquilo que ele, na condição de sujeito, constituiu-se historicamente como indivíduo e assim o afeto age como matéria política nesse corpo desamparado. Diante do desamparo, o sujeito é despossuído de seu modo de existência estabelecido, permitindo que os afetos circulem de outra forma e produzam novos modos de existência. A política do desamparo, assim como o procedimento de reduçâo, busca uma dinâmica dentro de um circuito de afetos que idealiza um corpo não automatizado, no qual os impulsos dos gestos não são condicionados. Busca-se, ao contrário, um corpo em errância ou um corpo em estado de devir . Essas inquietaçôes são, além de filosóficas, intensamente aprofundadas no âmbito das pesquisas cênicas, principalmente se entendermos a arte por uma perspectiva nietzschiana, ou seja, de que ela existe para não sermos destruídos pela realidade. Lembremos, por exemplo, o corpo sem órgãos de Antonin Artaud e a obsessão de Jerzy Grotowski pelo descondicionamento do gesto. Por extensão, um intenso desejo de reconfigurar os diversos poderes sobre um corpo normatizado, mecanizado, aprisionado e controlado. Esse é também um desejo da atual pesquisa, que investiga principalmente procedimentos de redução a partir do agenciamento entre as coisas que compóem a cena. 
Se, ao longo do processo de imersão do projeto, a ideia de despossuir foi constituída sobretudo pela desconstruçáo do ponto de vista diante das coisas, durante o processo de composiçáo, essa ideia foi estabelecida a partir do esvaziamento do significado e das possíveis representaçôes das coisas agenciadas, reduzindo-as ao que elas são como matéria e vibração. Um procedimento muito semelhante aos princípios do Teatro Zero, de Tadeusz Kantor, de 1964, que buscava novos modos de expressão cênica, distanciando-se dos paradigmas do teatro representativo. Sua própria relaçáo com os objetos em cena, assim como seu entendimento geral de encenaçáo, era de neutralizar as significaçóes e simbologias pré-estabelecidas para buscar novas formas de expressão. Com uma proposta bastante performativa, suas concepçóes cênicas dialogam diretamente com o que temos chamado de redução. Podemos identificar isso inclusive a partir de seus escritos, como o manifesto do Teatro Zero:

O teatro que chamo Zero não representa uma situação zero já determinada. Sua essência é o processo orientado até o vazio e às zonas zero. [...] Desmontado de toda organizaçáo que se forme. Decomposiçáo geral de toda forma. [...] Repetição automática. Desinformação. Deformação da informação. Decomposição da ação. $\mathrm{O}$ objeto se desembaraça de sua significaçáo ingenuamente sobreimpressa e de seu simbolismo que o camufla, revelando a autonomia de sua existência vazia (Kantor, 2008, p. 87-90).

Kantor, já nos anos 1960, compreendia que os modos de expressão da cena precisavam urgentemente desvincular-se de suas amarras representativas, pois o teatro havia se tornado refém de uma visão de mundo atrelada a um tipo controlado de subjetividade e sensibilidade. O que propomos aqui, assim como Kantor, Grotowski, Artaud e Samuel Beckett, é investigar modos de expressáo que reconfigurem nossa subjetividade, propiciando assim novos modos de existência. Além da abordagem filosófica por meio de uma política do desamparo de Safatle, ou processos de redução dentro de modos de existência para Lapoujade, buscamos também entender como isso pode ser reconhecido dentro de um processo criativo e seus possíveis desdobramentos.

Ao citar exemplos de criaçôes artísticas que atingiam seu limite formal de redução, seja John Cage com seus 4'33" de silêncio, o quadrado branco de fundo branco de Malevitch ou os White Paintings de Rauschenberg, Lapoujade, numa leitura deleuziana, propóe que procedimentos de esgotamento do modo de expressão, em suas múltiplas instâncias, possibilitariam a re- 
configuração de corpos, da subjetividade e da percepção (Lapoujade, 2017). O esgotamento discutido aqui é um termo abordado por Gilles Deleuze (2010b) e revisto tanto por David Lapoujade quanto por Peter Pál Pelbart (2016). Apesar de os autores refletirem sobre o esgotamento acima de tudo por um viés filosófico, eles também abordam o âmbito da estética e da criação, sugerindo a obra de Samuel Beckett como referência sobre esse tema.

Primeiramente, é importante diferenciar a ideia de esgotamento da ideia de cansaço. Este estaria inserido numa "dialética do trabalho e da produçáo: descansa-se para retomar a atividade" (Pelbart, 2016, p. 42) e, desse modo, o cansaço impede que o corpo seja afetado. Já o esgotamento pressupóe desconectar-se da noção de indivíduo, desestabilizando sua sensibilidade para entáo encontrar novos modos de afetar e ser afetado, ou seja, permitindo novos modos de existência. Para Pelbart (2016, p. 43), o esgotado é aquele que teve a força de "[...] produzir o vazio ou fazer buracos, afrouxar o torniquete das palavras, secar a ressudaçáo das vozes para se desprender da memória e da razão". Trata-se de um procedimento, assim como Safatle discorre sobre o desamparo, que objetiva despossuir as preconcepçóes de mundo e de indivíduo, abrindo-se assim para uma ação transformadora. Para Pelbart (2016, p. 413):

O esgotamento desata aquilo que nos 'liga' ao mundo, que nos 'prende' a ele e aos outros, que nos 'agarra' às suas palavras e imagens, que nos 'conforta' no interior da ilusão da inteireza (do eu, do nós, do sentido, da liberdade, do futuro) da qual já desacreditamos há tempos, mesmo quando continuamos a eles apegados.

Ao propor o esgotamento como conceito e procedimento de criação do projeto $A$ sombra dos outros pode-se compreender um engajamento filosófico tanto pelo movimento de transformaçáo nos modos de existência, quanto pelas possíveis reconfiguraçóes dos próprios modos de expressão. A noção de esgotamento, como modo de expressão, foi primeiramente pensada a partir do esvaziamento do significado e da representaçáo das coisas, além de suas possíveis e múltiplas formas de agenciamento. A composição principia então da ideia de organizar e agenciar as coisas: imagens, sons, textos, objetos e a experiência vivida daquele universo da imersão. 


\section{O Agenciamento das Coisas e suas Multiplicidades}

As imagens capturadas pelo registro em vídeo serviram como elementos centralizadores da composição, não apenas pela quantidade de material capturado, mas sobretudo porque um dos objetivos da imersáo foi o deslocamento de nosso ponto de vista diante da cidade, reconhecendo outros modos de existência. O entendimento de que o exercício de olhar as coisas por outra perspectiva é também um modo de despossuir nosso próprio entendimento de mundo. E foi por meio do dispositivo câmera que essa mudança de perspectiva se tornou ainda mais concreta. $\mathrm{O}$ modo de expressão cinematográfico trabalha com esta compreensão, de que a mudança do ponto de vista ou do ângulo do enquadramento pode alterar o discurso do objeto filmado. O cinema se constitui como composiçáo de imagem e qualquer interferência na imagem pode intervir consequentemente no seu discurso. Esse pressuposto foi integrado durante os registros do projeto, no qual buscávamos registrar as coisas por diferentes e múltiplas perspectivas. Entendemos que as imagens capturadas centralizariam nossa composição e, por isso, também optamos por trabalhar com três diferentes suportes de projeção, possibilitando agenciar três imagens distintas simultaneamente no palco. A seguir, a ilustração de como essas três imagens foram agenciadas entre si (Figura 5) e também como elas foram agenciadas no palco (Figura 6):

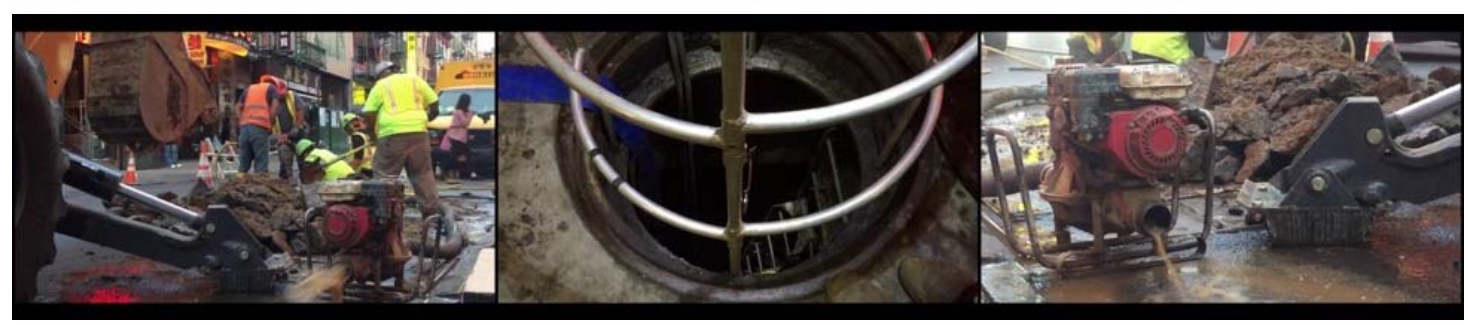

Figura 5 - Ilustração de três imagens agenciadas entre si. Fonte: Capturas de tela dos vídeos realizados pelo cineasta do projeto Peter Azen e pelo diretor Rodrigo Fischer entre setembro de 2017 e maio de 2018 na cidade de Nova Iorque. 

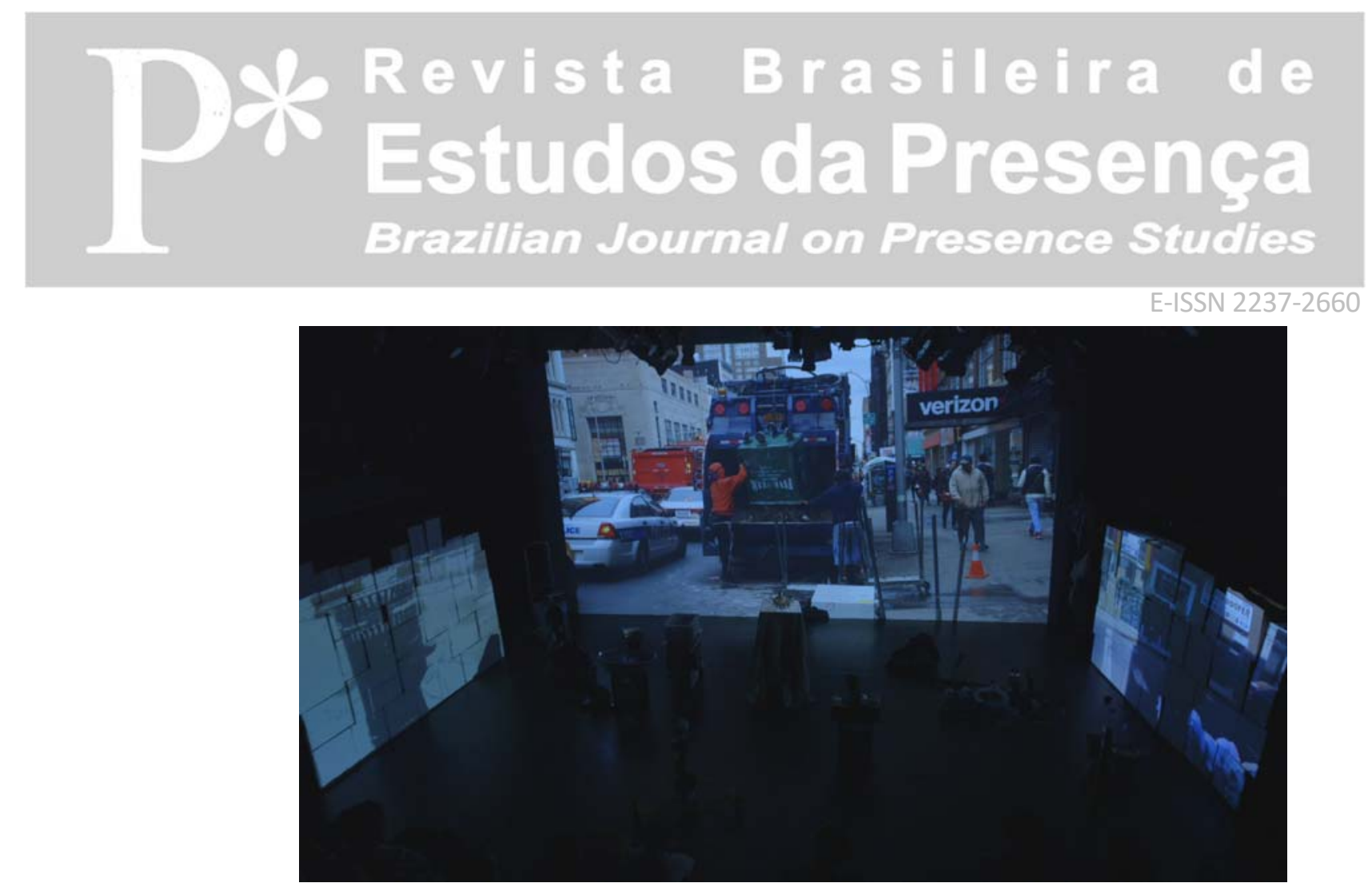

Figura 6 - Ilustração das imagens agenciadas no palco. Fonte: Imagem de Peter Azen no teatro Dixon Place, cidade de Nova Iorque (2018).

Além de pensar nas possíveis tensóes geradas entre as três telas, a composição das imagens foi elaborada por meio de uma montagem que priorizasse mais a duração de cada imagem do que uma construção espaçotemporal de seu sequenciamento. A proposta era pensar na materialidade e singularidade de cada imagem e considerar a sua potencialidade de evocar e adensar múltiplas camadas semânticas. Para Deleuze (2010a, p. 81-83):

É que a imagem não se define pelo sublime do seu conteúdo, mas por sua forma, isto é, por sua 'tensão interna', ou pela força que mobiliza para esvaziar ou esburacar, aliviar a opressão das palavras, interromper a manifestação das vozes, para se desprender da memória e da razão, pequena imagem alógica, amnésica, quase afásica, ora se sustentando no vazio, ora estremecendo no aberto. A imagem náo é um objeto, mas um 'processo' [...] O que conta na imagem não é o conteúdo pobre, mas a prodigiosa energia captada, prestes a explodir, fazendo com que as imagens nunca durem muito tempo.

A insistência de reduzir a imagem à sua materialidade e forma, delimitava que nosso discurso não se voltava para a representação de uma ideia, mas sim para a própria performatividade da imagem em sua variaçáo espaço-temporal, em sua vibração de luz, cor e composição. $\mathrm{O}$ interesse não era representar o universo que considerávamos subterrâneo, mas apresentar a potência daquele modo de existência, mostrar a matéria daquelas coisas aparentemente invisíveis. Por isso, inclusive, foi preciso que os objetos recolhidos durante a imersão estivessem presentes e vivos no palco, passando de 
uma virtualidade no contexto da cidade para uma possível atualização como um objeto artístico no palco.

Os objetos e lixos, despossuídos de seu valor e utilidade, foram organizados no palco para uma reconfiguraçáo, tanto a partir do agenciamento com outros elementos, como as imagens, quanto a partir de suas possíveis interaçóes com o espectador. Um dispositivo fundamental do projeto foi o de estabelecer um espaço cênico que o espectador pudesse visitar e com o qual pudesse interagir a partir das obras ou obras-lixo, como foi denominado. $\mathrm{O}$ espectador entrava por uma porta que dava acesso direto ao palco onde as obras estavam dispostas numa dinâmica de visitação, como se o espectador estivesse de fato numa galeria de arte. Eram ao todo 12 obras que permitiam, em alguma instância, a interação com o espectador.

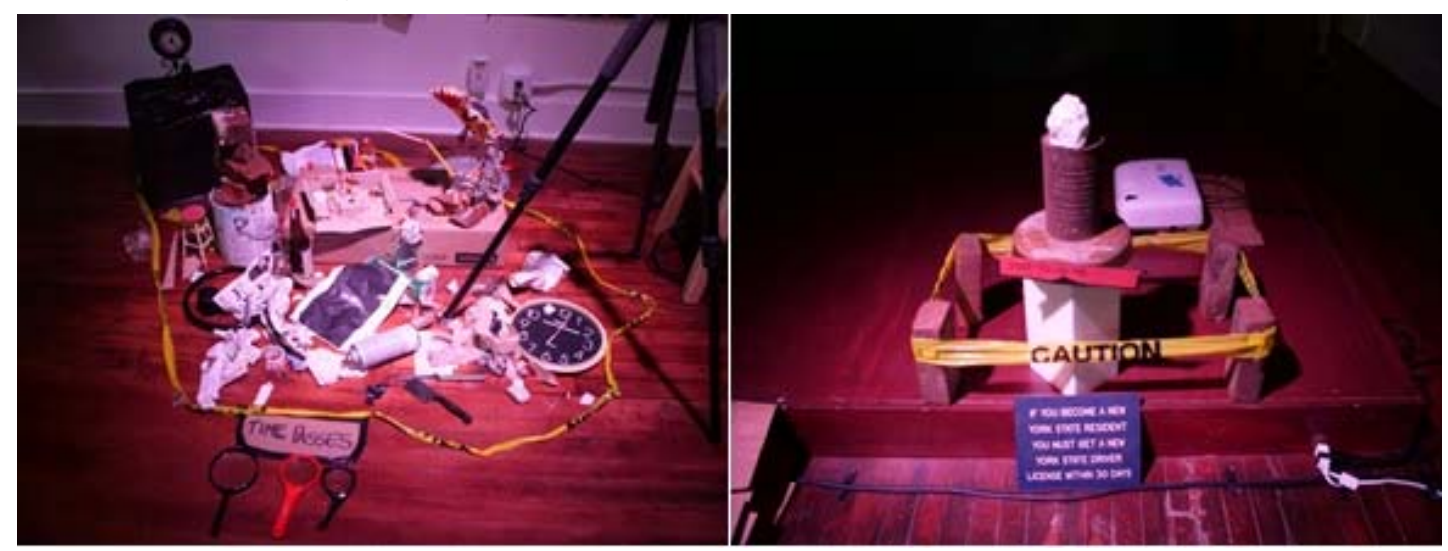

Figuras 7 - Duas obras do projeto. Fonte: Fotos de Rodrigo Fischer das obras expostas no teatro Dixon Place em Nova Iorque (2018).

A obra ilustrada na Figura 7, à esquerda, era chamada ${ }^{5}$ de Time passes (Tempo passa) e dispunha de algumas lupas para que o espectador pudesse olhar a obra-lixo por diferentes perspectivas e construir sua própria narrativa por seu intermédio. Já a obra ilustrada pela Figura 7, à direita, era intitulada como Don't touch me (Não me toque). Nessa obra, que era cercada por uma faixa escrita caution (cuidado), havia um objeto náo identificável de gesso que, durante a visitação, provocava apenas uma curiosidade pelo mistério e por sua possível valoração, já que ela era tão protegida. Porém, no decorrer do evento ${ }^{6}$, essa mesma obra era derrubada por um carro de polícia controlado remotamente pelo performer. Ao cair no chão, o objeto se quebrava e um líquido vermelho escorria por entre seus cacos e uma coisa aparentemente inorgânica se configurava em algo orgânico, vivo. $\mathrm{Na}$ realidade, todas as obras iam se reconfigurando durante a apresentação, ora a partir do agen- 
ciamento com as imagens, sons e textos, ora a partir da interaçáo com o corpo do performer ${ }^{7}$.

Para uma compreensão estrutural da obra apresentada ${ }^{8}$, gostaríamos de dividi-la em três momentos: 1) Visitação: configurada a partir do agenciamento das obras-lixo, videoinstalação, som e corpos dos espectadores; 2) Montagem fílmica: configurada a partir do agenciamento audiovisual de imagens projetadas em três telas, narraçóes sonoras e obras-lixo; 3) Perfomance: configurada a partir do agenciamento do corpo do performer, obras-lixo, imagens compostas em tempo real com câmeras, imagens previamente gravadas, sons, textos e narraçóes. A primeira parte começava com o já mencionado dispositivo de visitação, no qual o público interagia com as obras dispostas no palco, além de estarem envoltos por três grandes telas, sendo duas feitas com caixas de papeláo e uma sendo a própria parede do teatro, que se configuravam com uma videoinstalaçáo. Nesse momento da visitação, os vídeos exibiam imagens quase abstratas, feitas com uma câmera Super 8, enfatizando mais a vibração, o brilho e o contraste das imagens. Ao mesmo tempo o diretor e performer da obra ficava na parte de cima da plateia controlando luz e som em tempo real. Era uma espécie de interação invisível com os espectadores, já que eles possivelmente não percebiam que determinada luz ou som era acionado a partir de algo que eles faziam no palco. A ideia de invisibilidade permeou todo o agenciamento da obra numa constante busca de enfatizar a materialidade vibracional das coisas, como forma também de reduzir sua esfera de representação.

O segundo momento era caracterizado por uma montagem fílmica feita com o registro audiovisual da imersão. As imagens eram simultâneas e alternadas entre as três telas. Além das imagens projetadas, duas obras-lixo eram iluminadas enquanto duas vozes em off conversavam. O texto dessas vozes foi livremente inspirado nas personagens Hamm e Clov do texto Final de Partida, de Samuel Beckett (2010). O segundo momento encerrava quando as imagens de um carro de polícia passavam pelas três telas simultaneamente. Começava então o terceiro momento, com a continuidade do carro de polícia saindo da tela e um carro de polícia, controlado remotamente pelo performer, entrando no palco. $\mathrm{O}$ carro de polícia transitava por entre as obras e acionava sons de buzina ou de sirene como forma de ameaça às obras, até que em determinado instante o carro propositalmente coli- 
dia com uma das obras. Ele se chocava insistentemente até que a obra se danificasse, quando finalmente abandonava o palco. Era nesse momento que o performer, coberto por um saco de lixo preto, entrava no palco e começava a fazer composiçóes de imagem em tempo real com uma câmera. Sua primeira açáo, ainda na lateral do palco, era a de pegar o carro de polícia, único objeto que náo fora encontrado nas ruas, desligá-lo e jogá-lo num saco de lixo.

A presença do performer em cena era importante para compreendermos a interação dessa coisa orgânica com as outras coisas inorgânicas. A opçáo de cobrir o corpo e rosto do performer com saco de lixo foi necessária para literalmente despossuí-lo de sua noção de indivíduo, aproximá-lo da matéria de todas as outras coisas no palco, materializar a ideia de invisibilidade do corpo e trazer a ideia de embalagem, inspirada nas reflexóes de Tadeusz Kantor (2008). Ou seja, a intençáo não era representar o corpoobjeto em cena, mas sim reivindicar sua vibração por meio da embalagem que o protege e o aparta do uso comum, neutralizando, dessa maneira, sua significaçâoo original e sua possível simbologia. É a partir deste ponto, quando o corpo-objeto-embalagem está entre sua presença e ausência em cena, que eram realizadas diversas composiçóes, por meio do agenciamento de sua matéria com a materialidade das obras, imagens, sons, entrevistas e textos, que objetivavam atualizar o universo subterrâneo. Ou seja, instaurar virtualidades daquele modo de existência que identificamos durante a experiência errante pela cidade de Nova Iorque.

Importante ressaltar também que o uso da palavra teve uma ênfase em sua materialidade. Durante o processo de criaçáo, muitos textos foram reunidos e trabalhados: desde o próprio texto do Dostoiévski, entrevistas com pessoas que encontrávamos no universo subterrâneo até textos que iam se incorporando ao processo, como alguns poemas de Gertrude Stein e trechos de textos de Samuel Beckett. Inspirado pela forma da escrita de Stein, o ponto de partida da elaboraçáo dos textos estava numa esfera mais performativa. A proposta era de que "[...] em vez de representação de conteúdos linguísticos orientada pelo texto, prevalece uma 'disposiçáo' de sons, palavras, frases e ressonâncias conduzida pela composiçáo cênica e por uma dramaturgia visual que pouco se pautam pelo sentido" (Lehmann, 2007, p. 249). A composição dos textos de Gertrude Stein (1997) prioriza o uso das 
palavras a partir de sua sonoridade, ritmo, repetição e das múltiplas sensorialidades que as palavras e seu encadeamento proporcionam. A beleza das palavras, os cheiros e imagens que elas evocam. As palavras, nos textos de Stein, assim como estabelecido no projeto, se tornam mais objetos autônomos do que objetos simbólicos. Foi dentro dessa perspectiva que a palavra foi trabalhada em cena no projeto. O texto original em inglês foi escrito por Rodrigo Fischer e, considerando que sua proposta é de justamente explorar a sonoridade das palavras, a tradução aqui priorizou mais sua recriação poética e sonora do que sua esfera significativa. Segue a tradução:

Ela tem medo do que pensa. Ela acha que estar muito consciente das coisas é uma doença. Informação. Subordinação. Ela é doente. Porque o sofrimento nasce na consciência. Entre feijōes, reis, bufôes, gays, choróes. Porque? Arroz. Pó. Pausa. Silêncio. É uma mentira. Tempo morre. Agora essa mulher não acredita em absolutamente nada. Ela precisa apenas ser aceita, ser amada entre feijōes, reis, bufôes, gays, choróes. Porque? Tempo passa. Tempo cresce. Tempo basta. Tempo voa. Tempo morre. Para voar é preciso ter a coragem de enfrentar o silêncio do vazio. Eu não escuto nada. Minha vista está turva. Silêncio. Escuridão. Oquidão entre feijốes, reis, bufôes, gays, chorôes. Por quê? $\mathrm{O}$ vazio é um espaço de liberdade. $\mathrm{O}$ buraco. Oco. O esgoto. Ratos! Quem? O quê? O que é melhor, uma felicidade vulgar ou uma tristeza profunda? Ela deixa escorrer lágrimas quando ela se lembra, quando ela náo se lembra ser inteira. Ela se sente inteira, ele se sente inteiramente plena, ela está totalmente imersa numa espécie de plenitude?.

Esse texto, escrito a partir de uma das entrevistas e inspirado nos textos de Gertrude Stein, foi inserido no projeto como uma voz em off. Ele foi narrado pelo performer com uma ênfase maior no ritmo e na sensorialidade das palavras, reduzindo assim sua potência de significado para permitir outras esferas afetivas. A composiçáo da obra em todos os seus aspectos e agenciamentos foi determinada por uma tentativa de esvaziamento de seus possíveis significados e representações.

\section{O Esgotamento da Representaçáo como Invençáo de Mundos}

Como foi mencionado no começo do texto, a representaçáo é entendida aqui como uma busca para tornar presente uma noção específica de mundo. De um modo geral, o teatro ocidental, com algumas exceçóes ao longo de sua história, sempre esteve mais atrelado à ideia de representação. A partir dos anos 1970, e com uma intensificação a partir dos 1980 e 1990, 
muitas criaçóes passaram a enfatizar mais a esfera performativa do que a esfera representativa de suas obras. Nas abordagens de Deleuze (2010b), Lapoujade (2017) e Pelbert (2016), Samuel Beckett é uma figura central para se pensar possíveis anulaçôes da ideia de representação, principalmente a partir de suas últimas obras, como $O$ Inominável (2009) e $O$ despovoador (2008), em que o sujeito tem algo de pré-discursivo. Um sujeito que é muitas vezes materializado apenas pelo corpo da voz, talvez como algo que preceda à própria consciência e razão. $\mathrm{O}$ indivíduo e sua identidade não são preservados em sua obra. Geralmente por meio de uma catástrofe, as palavras são esgotadas e o que resta é o silêncio, a imobilidade, o vazio, ou seja, a linguagem e seu possível esgotamento. A catástrofe nas obras de Beckett é um pressuposto para o esvaziamento da razáo e uma maneira de reconfigurar a percepção para um mundo novo.

A hipótese do processo de criaçáo do projeto, ancorada principalmente pelo pensamento de Lapoujade, Deleuze, Safatle e Pelbert, seria a de pensar procedimentos de redução, desamparo e esgotamento em modos de expressão para instauraçáa de novos modos de existência e, consequentemente, a invenção de novos mundos. Tais procedimentos, em suas múltiplas abordagens, como subtração, desaceleração, esvaziamento, despossessão e desindividuação, são perspectivas ora práticas e ora poéticas, mas nunca como fórmulas maniqueístas. Lapoujade diz que dentro dessas esferas, que priorizam a redução, a percepçáo muda e "[...] onde certas pessoas verão apenas a abstração de uma qualidade pura, outras veráo a superfície refletora de movimentos, de deslocamentos ínfimos, induzidos por uma mudança de escala na percepçáo" (Lapoujade, 2017, p. 110). A redução, o desamparo e o esgotamento são compreendidos aqui como procedimentos para instaurar um plano que torne possível novas percepçóes, novos afetos e novos modos de existência.

A investigação daquilo que chamamos de universo subterrâneo, com suas existências mínimas e suas invisibilidades, apresentou pistas para compor uma obra que trabalhasse a descentralização do sujeito, permitindo novas formas de subjetivaçáo. Um novo ser nasce quando o desamparo permite que ele despossua sua forma controlada e normatizada de indivíduo. Despossuído de suas preconcepçóes de mundo, ele se abre para novas formas de percepçáo, para uma outra cosmovisão. $\mathrm{O}$ teatro, nessa perspectiva, urge 
por novos modos de expressão que não sejam reféns da representação, já que ela é guiada por uma visáo de mundo estabelecida. Um mundo em que os “conflitos já estão normalizados, codificados, institucionalizados" (Deleuze, 2010b, p. 54).

Diante dos tantos excessos pelos quais somos atravessados e a favor de processos que busquem reconfigurar noçóes de mundo, os procedimentos de redução, desamparo e esgotamento parecem urgentes dentro da criação. Gostaríamos de terminar com uma reflexáo de Deleuze que condensa esse anseio, ora real e ora utópico, por novos modos de expressão, novos modos de existência e invenção de novos mundos:

O teatro surgirá como o que não representa nada, mas apresenta e constitui uma consciência de minoria, enquanto devir universal, operando alianças aqui ou ali conforme o caso, seguindo linhas de transformaçáo que saltam para fora do teatro e assumem uma outra forma, ou se convertem em teatro para o novo salto (Deleuze, 2010b, p. 64).

\section{Notas}

1 O Grupo Desvio foi criado em 2001 pelo diretor Rodrigo Fischer, na cidade de Brasília, com o objetivo de investigar, experimentar e apresentar projetos teatrais com foco no processo criativo do ator. A partir de 2008, o grupo começa a se apropriar de novas tecnologias e poéticas audiovisuais para potencializar o discurso do ator. Em 2016, a interdisciplinaridade começa a atravessar as pesquisas do grupo, que passa a criar obras para galerias, museus, espaços urbanos e salas de cinema. O grupo é atualmente formado por César Lignelli, Fernando Gutiérrez, Gil Roberto, Márcio Minervino e Rodrigo Fischer.

2 O pós-doutorado foi realizado no Programa de Pós-Graduação em Artes Cênicas da Universidade de Brasília com supervisão da professora e também autora do presente artigo, Roberta Kumasaka Matsumoto. Com bolsa de fomento PNPD/CAPES, o pós-doutorado foi realizado entre os anos 2015 e 2019.

3 A cidade de Nova Iorque é dividida em cinco grandes bairros: Bronx, Manhattan, Queens, Brooklyn e Staten Island, sendo os mesmos subdivididos em áreas menores como, por exemplo: East Village, Chelsea, Bushwick, Astoria, Bayridge, entre tantos outros. O projeto percorreu os cinco bairros e as áreas de imersão foram determinadas principalmente pelas peculiaridades de cada regiáo. Por exemplo, Bedford-Stuyvesant, caracterizada por sua comunidade afroamericana; Sunset Park por sua comunidade chinesa; East Williansburg por 
sua comunidade judaica; Bayridge e a comunidade árabe; Astoria com uma população de brasileiros e gregos; entre tantas outras áreas de imersáo do projeto.

O conceito foi desenvolvido na tese Poéticas entre o cinema e o teatro: reflexóes sobre presença e atuação cênica a partir da obra de John Cassavetes, defendida por Rodrigo Fischer em 2015. O conceito, de um modo geral, sintetiza o momento em que o ator se coloca no instante, ouvindo e reagindo, buscando novas percepçóes de seus impulsos. O ponto de partida é priorizar a materialidade ambígua do corpo e seus gestos em detrimento de suas possíveis representaçôes. Uma ideia atravessada por conceitos como corpo sem órgãos de Antonin Artaud e devir de Gilles Deleuze.

5 Todas as obras tinham um título que podia sugerir alguma interação, como a obra don't touch me (não me toque); Leave something valuable (Deixe-me algo de valor) ou Dance with me (Dance comigo).

6 Chamamos de evento porque, apesar de o projeto ter sido apresentado num palco, ele não era caracterizado apenas como um modo de expressão teatral, já que outros modos de expressão foram integrados, como uma instalação audiovisual, obras visuais para visitação e o próprio cinema.

7 O performer Rodrigo Fischer era responsável também pela manipulação de todas as instâncias tecnológicas, como som, câmera, luz e projeção. Por exemplo, durante a primeira parte da apresentação, configurada pela interaçáo do público com as obras-instalaçóes, o performer permanecia na cabine controlando luz e sons. Para o público, esse momento era compreendido apenas como uma instalação, mas eles invisivelmente já constituíam parte da obra, na qual sons e luzes eram acionados a partir de específicas açóes no palco, como quando um dos espectadores vestia uma das obras, uma capa inspirada nas obras do Bispo do Rosário, e o performer acionava uma luz nesse espectador e colocava uma música específica para ele.

8 O projeto $A$ sombra dos outros estreou no dia 15 de junho de 2018 no teatro Dixon Place em Nova Iorque. Para acessar o vídeo na íntegra dessa apresentação, acessar o link: <https://vimeo.com/279953987>. Acesso em: 02 jun. 2019.

9 Do original em inglês: "She is afraid of her consciousness. She believes that being too much aware of things is an illness. Information. Subordination. She is sick. Why is suffering the sole origin of consciousness. Among beans, kings, queens, signs, rice, cries. Why? Rice. Rise. Up. Pause. Silence. It's a lie. Time 
dies. This time, this woman does not believe in anything. She just needs to be accepted, to be loved among beans, kings, queens, signs, rice, cries. Why? Time passes. Time grows. Time flies. Time goes. Time dies. To fly is necessary to have courage to face the terror of the void. I can't hear anything. My vision is blurred. Silence. Dark. Empty among beans, kings, queens, signs, rice, cries. Why? The void is the space of freedom. The hole. The spite. The cave. They fight. Who? What? Which is better, cheap happiness or exalted sufferings? She had tears coming in him when she was remembering, when she was not remembering being such a one. She is such a one, she is completely filled being such a one, she is entirely meaning to be such a one".

\section{Referências}

BECKETT, Samuel. O despovoador/Mal dito mal visto. São Paulo: Martins Fontes, 2008.

BECKETT, Samuel. Inominável. Rio de Janeiro: Biblioteca Azul, 2009.

BECKETT, Samuel. Final de Partida. Rio de Janeiro: Cosac \& Naify, 2010.

DELEUZE, Gilles. Diferença e repetição. Rio de Janeiro: Graal, 2006.

DELEUZE, Gilles. Cinema 2: imagem-tempo. São Paulo: Editora 34, 2010a.

DELEUZE, Gilles. Sobre o teatro: um manifesto de menos. Rio de Janeiro: Zahar, 2010b.

DOSTOIÉVSKI, Fiódor. Notas do subterrâneo. São Paulo: Bertrand Brasil, 1983.

FISCHER, Rodrigo. Poéticas entre o Cinema e o Teatro: reflexóes sobre presença e atuação cênica a partir da obra de John Cassavetes. 2015. Tese (Doutorado em Artes) - Programa de Pós-Graduação em Artes, Universidade de Brasília, Brasília, 2015.

KANTOR, Tadeusz. O Teatro da Morte. São Paulo: Perspectiva, 2008.

LAPOUJADE, David. Existências mínimas. São Paulo: N-1, 2017.

LEHMANN, Hans-Thies. O Teatro pós-dramático. São Paulo: Cosac \& Naify, 2007.

LEPECKI, André. 9 variações sobre coisas e performance. Urdimento, Florianópolis, UDESC, v. 2, n. 19, p. 95-101, nov. 2012. Disponível em: <http://dx.doi.org/10.5965/1414573102192012095>. Acesso em: 02 nov. 2018. 
PELBART, Peter Pál. O Avesso do niilismo: cartografias do esgotamento. São Paulo: N-1 Edições, 2016.

SAFATLE, Vladimir. O circuito dos afetos: corpos políticos, desamparo e o fim do indivíduo. São Paulo: Autêntica, 2016.

SOURIAU, Étiene. Los diferentes modos de existencia. Buenos Aires: Cactus, 2017.

STEIN, Gertrude. Tender Buttons: objects, food, rooms. Mineola: Dover, 1997.

Rodrigo Fischer é pesquisador Colaborador do Programa de Pós-Graduação em Artes Cênicas da Universidade de Brasília.

ORCID: http://orcid.org/0000-0001-8978-0434

E-mail: rodrigodesiderfischer@gmail.com

Roberta Kumasaka Matsumoto é professora do Programa de Pós-Graduação em Artes Cênicas da Universidade de Brasília.

ORCID: http://orcid.org/0000-0001-9352-402X

E-mail: robkmatsu@gmail.com

Este texto inédito também se encontra publicado em inglês neste número do periódico.

Recebido em 31 de janeiro de 2020

Aceito em 01 de junho de 2020

Editor-responsável: Gilberto Icle

Este é um artigo de acesso aberto distribuído sob os termos de uma Licença Creative Commons Atribuição 4.0 Internacional. Disponível em: <http://creative commons.org/licenses/by/4.0>. 